Connotas. Revista de crítica y teoría literarias 
CONNOTAS. REVISTA DE CRÍTICA Y TEORÍA LITERARIAS. Enero - diciembre 2013, es una publicación anual editada por la Universidad de Sonora, a través de la División de Humanidades y Bellas Artes, en el Departamento de Letras y Lingüística. Blvd. Luis Encinas y Blvd. Rosales s/n, Col. Centro, C.P. 83000, Hermosillo Sonora; Tel. (662) 2592 136, (662) 2592 157, <www.uson.mx>, <http://www.connotas.uson.mx, connotas@capomo.uson.mx>. Editor responsable: Rosario Fortino Corral Rodríguez. Reservas de Derechos al Uso Exclusivo núm. 04-2006-020714184900-102. ISSN: 18706630; ambos otorgados por el Instituto Nacional del Derecho de Autor. Licitud de Título núm. 13434 y de Contenido núm. 11007, otorgados por la Comisión Calificadora de Publicaciones y Revistas Ilustradas de la Secretaría de Gobernación. Este libro se publicó con el apoyo del Programa Integral de Fortalecimiento Institucional C/PIFI 2013-12934

Se autoriza la reproducción total o parcial de los contenidos de la presente publicación, siempre y cuando se acredite adecuadamente el origen de los mismos.

Datos de contacto para la publicación: División de Humanidades y Bellas Artes, Departamento de Letras y Lingüística; Apartado Postal 793, Col. Centro, C.P. 83000, Hermosillo, Sonora, México. Tels.: (662) 259-21-87, Tel-fax 212-55-29. Correo electrónico: connotas@,capomo.uson.mx Página web: http://www.connotas.uson.mx 
Connotas. Revista de crítica y teoría literarias

Núm. 13, año 2013

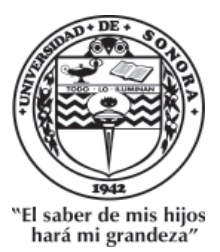

Universidad DE SONORA 


\section{UNIVERSIDAD DE SONORA}

RECTOR

Heriberto Grijalva Monteverde

VICERRECTORA

Arminda Guadalupe García de León Peñúñuri

Secretario General Académico

Enrique Fernando Velázquez Contreras

División de Humanidades y Bellas Artes

María Rita Plancarte Martínez

DePARTAMENTO DE LETRAS Y LINGǗ́sTICA

Ana Bertha de la Vara Estrada

César Avilés Icedo

Rosa María Burrola Encinas

Fortino Corral Rodríguez

Leticia Martínez Figueroa

Jesús Abad Navarro Gálvez

Gabriel Osuna Osuna

María Rita Plancarte Martínez

DIRECTOR

Fortino Corral Rodríguez

Giuseppe Bellini

Universidad de Milán

Luis Beltrán Almería

Universidad de Zaragoza

Helena Beristáin

Universidad Nacional Autónoma de México

Raúl Bueno-Chávez

Dartmouth College

Evodio Escalante

Universidad Autónoma Metropolitana

Beatriz González-Stephan

Rice University

Aníbal González

Yale University

Aurelio González Pérez

El Colegio de México

Yvette Jiménez de Báez

El Colegio de México

Nelson Osorio Tejeda

Universidad de Santiago de Chile
CONSEJO INTERNACIONAL

Carlos Pacheco

Universidad Simón Bolivar

Rafael Olea Franco

El Colegio de México

Joan Oleza Simó

Universidad de Valencia

Julio Ortega

Brown University

Luz Aurora Pimentel

Universidad Nacional Autónoma de México

Susana Reisz

The City University of New York

José Carlos Rovira

Universidad de Alicante

Charles Tatum

The University of Arizona

Jorge Urrutia

Universidad Carlos III de Madrid

Emil Volek

Arizona State University 


\section{Índice}

\section{Artículos}

Una hermenéutica analógica para la literatura

Mauricio Beuchot Puente

La obra de Jorge Luis Borges durante la década de 1930: estudio de algunos elementos para la conformación de su poética en Discusión (1932)

Daniel Zavala Medina

Metáforas de la locura y la muerte en "Río subterráneo"

de Inés Arredondo

Gabriel Osuna Osuna

La alteridad como vector de la construcción del yo: La muerte me da de Cristina Rivera Garza y El Gran Vidrio de Mario Bellatin Véronique Pitois Pallares

Uno soñaba que era rey de Enrique Serna: un espacio de contradicción Claudia Gidi

Una angustia compartida. Análisis de la voz narrativa en Mi hermano Carlos de Jorge López Páez

Jorge Antonio Muñoz Figueroa

De Los perros románticos y otros poemas de Roberto Bolaño Marina Martínez Andrade 
Las novelas del Crack, multiplicidad y superposición de mundos Ramón Alvarado Ruiz

La construcción del "otro" en la Relación de la jornada de Cíbola de Pedro Castañeda de Nájera

Guillermo Martínez Sotelo

Destino e historia en Margarita, está linda la mar de Sergio Ramírez

María Rita Plancarte Martínez

\section{Notas}

Identidad negada y mundo al revés en Santa María del Circo de David Toscana

César Avilés Icedo y María Elena González Borgaro ....... 203

"El buen ejemplo" de Vicente Riva Palacio: la historia de un cuento

Marco Antonio Chavarín González

Organización descriptiva en Catarina de San Juan, princesa de la India y visionaria de Puebla

Silvia Guadalupe Alarcón Sánchez

Genealogías en Todo aqui es polvo de Esther Seligson. Lectura a partir de los epígrafes

Luz Elena Zamudio Rodríguez

\section{Reseñas}

Martha Elena Munguía Zatarain. La risa en la literatura mexicana (apuntes de poética)

Silvia Alicia Manzanilla Sosa 
Véronique Pitois-Pallares. El arte del fragmento: El Gran Vidrio de Mario Bellatin

Julio César Zárate Ramírez .......................................................... 255

Nicolás Kanellos. Hispanic Immigrant Literature: El sueño del retorno

Josué Gutiérrez González

Dante Salgado. Brevísima relación de la idea de amor en Occidente

Diana Vanessa Geraldo Camacho

Mara L. García. Paco Yunque: una mirada crítica

Juan Paredes Carbonell

Abstracts

Résumés

293

Normas editoriales

303 



\title{
La alteridad como vector de la construcción del yo: La muerte me da de Cristina Rivera Garza y El Gran Vidrio de Mario Bellatin
}

\author{
Véronique Pitois Pallares*
}

Resumen:

Este trabajo, dedicado a dos novelas y dos escritores contemporáneos, La muerte me da de Cristina Rivera Garza y El Gran Vidrio de Mario Bellatin, trata de evidenciar la manera en que las múltiples representaciones de la alteridad participan en la construcción textual del yo narrador, hasta convertirse en un elemento proteiforme e indispensable de este proceso. Se evocará, por ejemplo, el motivo de la metamorfosis tal como aparece en las novelas de Bellatin y Rivera Garza, en sus numerosas variantes: metamorfosis voluntaria, padecida o soñada, temida o esperada, de sí mismo o del otro... De igual modo nos enfocaremos en las manifestaciones discursivas y narrativas de la angustia o del gozo del desdoblamiento. Lo que se podría caracterizar como la escritura de la esquizofrenia nos llevará a estudiar su imagen en negativo: la escritura esquizofrénica de Mario Bellatin, esta pluma que no deja de contradecirse y desdecirse. La figura del otro llega a constituir un vector de introspección del yo narrador, por reacción ante la incomprensión ajena y la imposibilidad de comunicar debidamente con el otro, o al identificar al otro como una "extensión" de la introspección propia. Se verá finalmente que en última instancia, la figura del otro interviene como una alternativa salvadora, una vía de escape que permite soñarse otro, revelarse en el otro, en la ficción de sí.

\footnotetext{
* Université Paul Valéry Montpellier 3.
} 
Palabras clave:

Identidad, alteridad, introspección, álter ego, invención de sí.

En el año 2007 se publican en México El Gran Vidrio de Mario Bellatin y La muerte me da de Cristina Rivera Garza, en Anagrama y Tusquets, respectivamente. Por muy diferentes que sean, ambas novelas presentan similitudes que quizás se puedan relacionar con el anhelo experimental compartido por sus autores. Una de ellas es la dimensión que cobra la introspección en ambos relatos, aunque la propuesta estilística de los dos autores coincide en más de un aspecto.

Efectivamente, la mayoría de las obras recientes de Bellatin y de Rivera Garza se caracterizan, si no por cierto hermetismo, sí en todo caso por sus peculiaridades estilísticas y escriturales. En estos dos libros, el lenguaje aparece como un elemento maleable más allá de las exigencias sintácticas, hasta rondar la ilegibilidad. Abundan las frases breves, nominales o participiales y las enumeraciones de palabras sueltas, separadas por puntos, evidenciando de este modo lo hiriente, lo disparatado o lo fugaz del lenguaje. Por otra parte, el absurdo y el onirismo trasparecen en ambos textos y llegan a caracterizar la trama misma, las acciones de los personajes o su percepción del mundo. Los protagonistas mantienen así una relación confusa con su entorno, con su universo, como si de alguna manera se encontraran desconectados de su realidad o estuvieran parcialmente en desfase con ella. Su ritmo de vida suele ser diferente del que adopta la sociedad que los rodea: entre otros ejemplos, la Cristina de La muerte me da se presenta como una mujer que corre por el gusto de correr; uno de los protagonistas de El Gran Vidrio se aleja de sus raíces culturales latinoamericanas al convertirse al islam sufí; otro de los personajes es un niño que vive recluido en una institución psiquiátrica, al margen de la sociedad.

Aunque se podría alargar la precedente lista de características compartidas por las obras de ambos escritores mexicanos, y esta lista requeriría, sin lugar a dudas, una argumentación sólida y un análisis textual que la justifique, en este trabajo nos limitaremos a otro rasgo que comparten las novelas La muerte me da de Cristina Rivera Garza y 
El Gran Vidrio de Mario Bellatin: la importancia particular que adquiere la dinámica introspectiva de los narradores.

En la primera, la narradora, que casualmente resulta llamarse como la autora y ser, a la par que ella, profesora universitaria, encuentra el cadáver de un hombre castrado en un callejón de la ciudad. Conoce entonces a la Detective y a su asistente Valerio, y forma parte del proceso de investigación de lo que será referido como el caso de los hombres castrados, tras el descubrimiento de otros cuerpos masculinos mutilados. Después de un primer capítulo marcado por una focalización interna en primera persona, aparecen nuevas formas de focalización interna, ya sea con narraciones en segunda y tercera persona para referir los pensamientos de Valerio o de la Detective, o con el conjunto de cartas anónimas firmadas por una misteriosa Viajera del Vaso Vacío. En ese popurrí entran también un informe policial que adopta rasgos del diario íntimo, un artículo académico dedicado a la poeta Alejandra Pizarnik, y un libro de poemas. Los investigadores pretenden descifrar los mensajes codificados de un asesino adepto de las metáforas y epígrafes para resolver el caso, pero la pesquisa policíaca se ve rápidamente opacada por una investigación íntima, psicológica, en la mente laberíntica de los personajes. Con tal de confundir al asesino, buscan comprender sus motivaciones y para ello se proyectan tanto en el papel de la víctima como en el del asesino. Esta identificación los obliga a enfrentarse con sus bajos instintos, con su deseo, sus miedos íntimos y su incompartible soledad.

En la novela de Bellatin, astutamente subtitulada "Tres autobiografías", tres narradores en primera persona relatan su autobiografía para después llegar a confundirse entre sí y con el autor. En el primer capítulo, un niño de edad indefinida relata en trescientas sesenta frases numeradas y separadas por un punto y aparte cómo su madre lo saca secretamente de la Escuela Especial en la que se encuentra recluido, y lo lleva a exhibir su desnudez y sus genitales en unos baños públicos a cambio de todo tipo de objetos. Afirma que según lo requiere una tradición ancestral, en cuanto se desvanezcan los extraordinarios atributos físicos que lo hacen digno de admiración, su madre lo matará al castrarlo sin piedad. Llega a recordar el pasado, cuando 
la familia era unida, antes del abandono paterno y del consiguiente mutismo patológico de la madre; sin embargo, la memoria y el juicio del chico fallan, y él mismo señala las incoherencias de su discurso.

En el segundo capítulo, el narrador es un escritor latinoamericano convertido al islam sufí: relata un sueño místico que involucra a una sheika y le inspira para escribir un cuento... jerótico! En una serie de digresiones, menciona sucesos de su juventud y llega a confundir la cronología del sueño (metadiegética) y la cronología de la realidad (diegética).

En el tercer y último capítulo, el narrador cambia de apariencia y de identidad varias veces mientras va presentando, negando y reafirmando sucesivamente cada una de las tres identidades ostentadas: la de un joven acompañado de su novia alemana, la de una niña de cuarenta y seis años -la menor de una familia que vive constantemente bajo la amenaza de ser expulsada de su casa-, y finalmente la del escritor Mario Bellatin, que por una travesía de esa niña reconoce a unos críticos literarios en el metro mientras él mismo viaja sin boleto. Finalmente, estas tres identidades se confunden y se mezclan con la del niño de los baños públicos y del escritor sufí para conformar un yo narrador múltiple, inestable y onírico.

Esta puesta en escena de la introspección, la búsqueda y la construcción del yo narrador o de los yoes narradores constituyen uno de los principales núcleos de estas dos novelas. En los múltiples recorridos intimistas por la memoria, los sueños y las fantasías de los protagonistas destacan diversas manifestaciones de la alteridad y se imponen como un nuevo vector de exploración del yo. Nos interesa ver en este trabajo en qué medida el otro representa un elemento - ¿freno o motor?, ¿freno y motor? - en la construcción y la evolución del yo. Asimismo, cabe preguntarse de qué manera y bajo qué forma las distintas figuras de la alteridad se manifiestan en el espacio textual de la introspección. Esta emergencia del otro en unos relatos esencialmente egocéntricos se produce en gran parte de manera indirecta, con el solo esbozo fantasmagórico y huidizo de una figura irremediablemente ausente.

En las dos novelas, la alteridad se manifiesta a veces en la presencia textual de un personaje que funge como representante-casi 
por antonomasia- del otro. Esta presencia puede resultar de la evocación o del recuerdo de un familiar, o paradójicamente de la ausencia formal de un interlocutor presente entre líneas, que disfraza el diálogo de monólogo, o viceversa. En otras ocasiones la alteridad surge y se impone no tanto frente al protagonista de la introspección sino en él, como una variante de su propia personalidad, una alternativa a sí mismo. Este motivo del álter ego se declina de dos maneras: la temática latente de la metamorfosis, y la creación imaginaria por parte del narrador de un doble que funge a la vez como espejo y como observador crítico y distanciado de sí mismo. En ambas novelas, la alteridad, real o imaginaria, se convierte en un elemento determinante en la construcción y la realización de sí mismo. Estudiaremos primero cómo en estos relatos la alteridad contribuye a revelar el yo, para luego focalizarnos en las implicaciones de la metamorfosis en tanto que intrusión recíproca del otro en el yo y del yo en el otro, $\mathrm{y}$ finalmente ver que, ante la falta o la insuficiencia de la alteridad, el sujeto de la introspección elabora estrategias propias para sustituir al otro de carne y hueso.

\section{El otro, revelador del yo}

Tanto el universo narrativo de La muerte me da como el de El Gran $V$ idrio se caracterizan por su aridez relacional o incluso su incomunicación, que se manifiestan de manera recurrente en las obras de los dos autores. En la novela Damas chinas, por ejemplo, Bellatin retrata a un médico que pone fin, fría y calculadamente, a los días de su hijo drogadicto. En Shiki Nagaoka: una nariz de ficción, el poeta japonés epónimo sufre constantes humillaciones por parte de sus compañeros del monasterio, quienes se burlan despiadadamente de su nariz de tamaño descomunal; abandonado por su familia, este creador de un libro imprescindible -aunque intraducible- permanecerá incomprendido hasta su muerte. En Salón de belleza, el salón se convierte en un moridero en el que los enfermos no reciben visita alguna, ni la mínima señal de compasión por parte del dueño. La narradora de $\mathrm{La}$ escuela del dolor humano de Sechuán narra con el orgullo que nace del 
trabajo bien hecho cómo logra ahogar en una fuente a los niños designados, y se ufana de nunca haber fracasado en esta tarea. A estos contados ejemplos de un fenómeno general y polifacético, se aúna la casi ausencia textual del discurso directo, que subraya la falta de comunicación que conocen estos personajes sumidos en un mundo violento, inhóspito, a veces cruel.

En el mundo narrativo de Cristina Rivera Garza, si bien los diálogos o las ocurrencias de discurso directo no faltan, la comunicación entre los protagonistas desemboca a menudo en una incomprensión mutua. Recuérdese el narrador de La cresta de Ilión, que se siente excluido al constatar que las dos mujeres que se establecen en su casa hablan un lenguaje desconocido al que no tiene acceso, o las citas de frases en el idioma imaginario de Brobdingnag, el reino de los gigantes de Los viajes de Gulliver, en La muerte me da. Por otra parte, en estas novelas la vida social de los protagonistas parece ser relativamente "raquítica", limitada a una rutina repetitiva y sentimentalmente pobre. A diferencia de lo que ocurre en la obra de Bellatin, estas dos novelas de Rivera Garza describen un cambio y una aceleración de la rutina de los personajes a partir del elemento perturbador que da inicio a la historia narrada. Asimismo, la llegada de la mujer que se presenta como Amparo Dávila en La cresta de Ilión o el descubrimiento del primer cadáver de hombre castrado en La muerte me da impulsan a los protagonistas a salir de su vida rutinaria, de su soledad, para interactuar, relacionarse y enfrentarse con otra gente, sin por ello abandonar su soledad íntima ni la torpeza que caracteriza sus intentos por comunicar con la alteridad.

Tal como lo recuerda Mijaíl Bajtín en Yo también soy (Fragmentos sobre el otro), la filosofía del lenguaje establece el papel preponderante del aprendizaje del lenguaje (recepción y apropiación) en la construcción de la subjetividad de un individuo. Esta adquisición supone necesariamente una situación de comunicación con el entorno humano, situación que le permite al niño identificarse como un yo singular, único, frente a una alteridad múltiple y plural. Cabe aquí interrogarse, en los casos brevemente evocados de comunicación ardua, estéril o ausente, qué implicación tendrá en términos de construcción de la identidad de los protagonistas. 
En El Gran Vidrio el tema de la comunicación es efectivamente objeto de dificultades o de tensiones: el personaje del tercer capítulo es tartamudo y mitómano, y llega a afirmar: "no hubo tampoco una lengua materna que recuerde. Estoy incapacitada para comunicarme" (153). Por otra parte, el protagonista del primer capítulo, el niño recluido en una Escuela Especial, nunca comunica con su madre, lo que él mismo explica en los siguientes términos: "a estas alturas es absurdo dirigirle la palabra. 205. Lo más probable es que se esconda detrás de uno de sus lápices y me muestre el rostro pintado con los colores más extraños que se pueda imaginar" (45). Este caso inicial es particularmente representativo de la manera en que la incomprensión y la ausencia de diálogo con el otro influyen en la construcción del yo introspectivo, sobre todo tratándose de un niño y de su madre. Bajtín explica: "todas las primeras definiciones de sí mismo y de su cuerpo, son recibidas por el niño de la boca de su madre y de las personas cercanas" (69). En el caso del personaje narrador de "Mi piel, luminosa", la falta de dichas definiciones (debida al mutismo materno) se traduce por una carencia esencial en la constitución y el reconocimiento de su propia identidad. Por ejemplo, es incapaz de recordar elementos importantes y constitutivos de su pasado y esta imposibilidad nace directamente de la ausencia de diálogo con la madre:

200. No tengo seguridad, eso sí, de que sean ciertas muchas otras cosas, aparentemente más importantes, no sólo de mis compañeros actuales sino especialmente de mi vida privada. 201. No sé, por ejemplo, el número de hermanos que he tenido. 202. He olvidado asimismo el rostro de mi padre. 203. Quizá preguntar a mi madre disiparía las dudas.

204. Pero a estas alturas es absurdo dirigirle directamente la palabra. (Bellatin 45)

En otra ocasión, este silencio le impide aclarar dudas relativas a su identidad propia, a su personalidad: "77. '¿Por qué me encuentro matriculado en una Escuela Especial?', es una pregunta que no dejo nunca de hacerme. 78. No creo que alguien tenga una respuesta se- 
gura, ni siquiera mis compañeros de reclusión" (20). Sin embargo, relata los numerosos esfuerzos que hizo su madre para que él ingresara en esa institución, esfuerzos que en muchos casos parecen una auténtica tortura, y que permiten sacar una doble conclusión: la primera, y quizás la más obvia, es que si alguien puede tener elementos de respuestas sobre la razón de su "reclusión”, esta persona es lógica y claramente su madre. La segunda conclusión tiende más al análisis textual del relato de los experimentos que la madre del niño narrador llevó a cabo "para conseguir de una manera más efectiva [su] futuro ingreso en la Escuela Especial" (24):

97. Entre otras acciones, me colocaba unos lentes con los que la realidad se trastocaba hasta convertirse en una presencia irreconocible, capaz únicamente de producirme desagradables mareos.

98. En otras ocasiones no me dejaba respirar, tapándome la cara con la almohada hasta que me sentía morir.

99. Una vez trató de introducir mi cráneo dentro de una calavera de cartón que guardaba con fines desconocidos.

100. Cierta mañana en que me descubrió gastando en caramelos un dinero que había caído del bolsillo de un muchacho, me chamuscó las manos en un fuego que encendió con el solo propósito de llevar a cabo su lección. (24)

Esta "serie de experimentos" (24), como lo refiere púdicamente el narrador, sería clasificada por cualquier tribunal del mundo como un acto de tortura física y psicológica caracterizado por su crueldad y por la humillación que supone. Si bien todas estas prácticas afectan la integridad física del niño, los castigos de los lentes y de la calavera de cartón son particularmente significativos porque influyen en la subjetividad del individuo: por una parte lo disfrazan, y por otra, trastocan sus posibilidades de aprehender el mundo, de situarse en él. Finalmente, el tono frío y desapasionado del narrador-víctima indica precisamente una falla o anomalía en la percepción que tiene de sí mismo: ni siquiera considera estos actos como abusos, sino como simples experimentos. La construcción de la subjetividad del perso- 
naje se ve complicada en este caso por un proceso de despersonalización y de objetivación del yo: la desimplicación emocional revela la frontera que separa el yo narrador de su objeto - el yo narradocomo si fuesen dos entidades distintas y distantes.

Ante las insuficiencias en el proceso de construcción identitaria, el yo narrador, a modo de compensación, se focaliza con cierta angustia en una característica física que parece ser su único vínculo con el mundo exterior, con la alteridad: la brillantez de su piel y de sus genitales en particular. Pretende haber heredado este don de un antepasado suyo y trae a colación una anécdota presentada como parte de la mitología familiar. Trátese de una invención de un niño en busca de identidad y que establece vínculos con ancestros suyos con el fin de legitimar su pertenencia a un linaje y así poder definirse mediante y respecto a un árbol genealógico, o bien de una auténtica tradición familiar, o aun de un cuento cruel inventado por la madre, el destino del antepasado (castrado por su propia madre en cuanto se desvanecieron sus atributos) le permite al niño imaginar su propio porvenir, proyectarse en el futuro. Por más insignificante y grotesco que parezca, este rasgo físico le permite diferenciarse de los demás, volverse excepcional, extraordinario ante el mundo y ante su propia mirada. Real o imaginada, esta casi deformidad física se convierte en un rasgo definitorio de sí mismo, de ahí que considere su desaparición con tremenda angustia, como un presagio de muerte inminente. Más allá de la tremenda amenaza de muerte por castración, la declinación de este atributo que le permite distinguirse de la multitud, de la alteridad, es percibido como una disolución de su ser.

Desde esta perspectiva, la castración de los hombres asesinados en La muerte me da es doblemente significativa: por una parte, le resta un rasgo definitorio al cuerpo, le quita lo que permitía que el sujeto se afirmara como un varón ante la alteridad femenina; por otra parte, le quita el nexo, el vínculo físico mediante el cual se podía conectar y enfrentar con esa alteridad femenina. En cuanto a la mutilación sacrificial, Bataille habla de: "[l] rupture de l'homogénéité personnelle, la projection hors de soi d'une partie de soi-même" (23) [La ruptura de la homogeneidad personal, la proyección fuera de sí de una parte de sí mismo (La traducción es mía)]. En este caso el órgano sexual tiene 
una carga extremadamente simbólica, dado que es a la vez un elemento de definición de la identidad y un órgano de reproducción, es decir, un medio para conectarse con la alteridad y así crear otra alteridad. La castración representa entonces un intento de apropiación o de negación absoluta de la identidad de la víctima, absoluta en tanto que le cierra el acceso a la alteridad y a la posibilidad de recobrar una identidad en el contacto con el otro.

Antes de llegar a estos extremos de violencia y de negación simbólica de la identidad ajena, la novela presenta también a unos personajes que, de alguna manera y parafraseando a la narradora del capítulo final de El Gran Vidrio, están incapacitados para comunicar.

Las primeras páginas de La muerte me da insisten efectivamente en los problemas con los que se enfrenta la narradora a la hora de expresarse: "Es difícil explicar lo que uno hace. Las causas. Las consecuencias. El proceso. Es difícil explicar lo que uno hace sin echarse a reír o a llorar, desmesuradamente" (Rivera 20). En este breve capítulo, el lector entiende que la narradora va contestando las preguntas de un oficial de policía, pero del diálogo sólo aparecen las respuestas de Cristina, en cursivas, subrayando aún más la ausencia de comunicación y la incomprensión crónica que caracterizan gran parte de los intercambios verbales. Al mismo tiempo, se dirige en segunda persona al muerto, como si éste fuera un interlocutor común y corriente, del que tampoco -claro está- se plasman las respuestas: "Estoy segura de que sabes silbar. Tienes ese tipo de boca sobre la boca semiabierta por la que no entra el aire ni la noche. Mi primer" (19). Más tarde, el asistente de la Detective, Valerio, la recordaría como "una profesora que solía sostener largas conversaciones con seres que él no podía ver" (228). Este procedimiento de ausencia formal del destinatario del discurso tiene además la particularidad de radicalizar la focalización interna del texto hasta el grado de ocultar al interlocutor, quien se convierte entonces literalmente en un puro pre-texto, que antecede y provoca el texto, del que permanece irremediablemente excluido. Sin embargo, esta presencia no plasmada del otro exige de la protagonista que se presente, que se explique y que sondee sus adentros, exponiéndose así ante el lector. Quizás incluso sea más revelador de su yo íntimo ese monólogo interior que 
formula para sí misma aunque -como se sabrá después por Valerioen voz alta, y que corresponde de alguna manera con: "El escandaloso rumor del yo dentro de la pecera oscura del esqueleto" (19).

A través de los ejemplos mencionados supra, se puede observar que el otro asume un papel contradictorio en la dinámica introspectiva de los narradores: la incomprensión sistemática y eventualmente la ausencia total de comunicación constituyen en primera instancia un obstáculo porque limitan el intercambio con el otro, necesario para plantearse como yo, frente a un tú y diferente de ellos. Para compensar esta casi ausencia del otro, el yo busca nuevas vías de reconocimiento y de afirmación de sí mismo, aferrándose a lo que según él lo caracteriza o sumiéndose en un proceso introspectivo frenético. Ello se traduce en El Gran Vidrio por las interrogaciones del niño sobre su pasado, su familia y su esfuerzo por preservar la memoria de los tiempos amenos, anteriores a la ruptura familiar. En La muerte me da, la primera ilustración de este fenómeno sería la logorrea de la narradora Cristina con tal de asimilar y superar el choque emocional implicado por el descubrimiento del primer cadáver.

La ausencia o falta del otro contribuye así paradójicamente a la afirmación del yo y participa por ende en revelarlo. Por otra parte, en los dos relatos esta dificultad extrema por comunicar con el otro permite resaltar la frontera esencial que aísla al yo de todo lo que lo rodea, pues los pensamientos y emociones de los dos protagonistas, al no poder ser compartidos con nadie, se vuelven aún más egocéntricos y evolucionan de manera casi autárquica. Un nuevo ejemplo de esta frontera que separa al yo del otro se encuentra en $L a$ muerte me da, cuando la Viajera del Vaso Vacío escribe:

Estabas claramente fuera de ti y, a pesar de eso, o tal vez a causa de eso, por encontrarte a todas luces fuera de ti, tenías el semblante de alguien con quien se podía conversar. Alguien, es decir, que sabía escuchar. Porque para poder escuchar, ¿lo sabías?, siempre es necesario estar un poco fuera de uno. Fuera de sí. (77)

Esta última expresión, "Fuera de sî", no deja de remitir al análisis que hace Bataille de la mutilación sacrificial ("la proyección fuera de sí 
de una parte de sí mismo”), y permite establecer una relación entre la castración de los cadáveres y este mensaje escrito por la persona que se asume y se presume asesina. Supone sobre todo que la única posibilidad de comunicación radica en una toma de distancia consigo mismo, un movimiento que, en términos de Deleuze y Guattari (23), se podría definir como una desterritorialización espiritual y física que le permite al yo abandonar algo de sí mismo para reterritorializarse en los territorios del otro o en una tierra de nadie propicia al intercambio. ${ }^{1}$

\section{La metamorfosis entre amenaza y tentación}

En El Gran Vidrio, la angustia identitaria del niño narrador de "Mi piel, luminosa", obsesionado por la brillantez de su piel y por la perfección excepcional de sus genitales, remite a algo más que al miedo a la disolución del yo, pues implica el temor al cambio, a la intrusión de algo extraño, ajeno, que afecta al yo y lo hace, parcial y paulatinamente, otro. Dicha intrusión de lo otro no es sino la evolución propia del cuerpo del niño, pero aún así esta metamorfosis es considerada como una fuerte amenaza. Como se ha mencionado al inicio de este trabajo, el narrador del capítulo siguiente, titulado "La verdadera enfermedad de la sheika", es un hombre latinoamericano a quien le falta un brazo desde que nació. Si la deformidad no parece pesarle -le es propia, contribuye a distinguirlo y a definirlo-, vive en cambio la imposición de una prótesis para reemplazar la extremidad faltante como una auténtica alienación:

Desde que nací mis padres se empeñaron, de manera casi obsesiva, en que utilizara una prótesis que supliera mi brazo faltante. Lograron inculcarme la necesidad de utilizarla [...]. Fue de tal magnitud la obsesión de mis padres, que tuvieron que pasar más de cuarenta años para que, en medio de una

\footnotetext{
${ }^{1}$ Desde esta perspectiva, la castración puede entenderse como una tentativa del asesino de obligar al otro a comunicar, en un trágico intento por proyectarlo fuera de sí.
} 
suerte de viaje iniciático a la India, arrojara el último brazo al río Ganges. (80-81)

El mismo personaje conoce otro proceso de metamorfosis, en este caso voluntaria y consciente, que se evidencia en su conversión religiosa al islam sufí que, casualmente y según el propio narrador, implica una manera inédita de conectarse con el otro:

No en vano en la religión islámica el milagro es un libro y nosotros somos sólo una letra de ese libro. Es quizás ésa la razón, ser sencillamente una letra de un alfabeto infinito, por la que cuando algún practicante del sufismo se desplaza en avión o en tren acostumbra pasar por una serie de experiencias fuera de lo común. [...] sienten el inusitado impulso de elegir, entre el grupo de desconocidos que suele poblar las salas, a alguna persona de la que nunca en la vida les gustaría desprenderse. Como una letra que buscara pegarse a otra para formar una palabra. (98-99)

Además de proponer una nueva vía de superación de sí mismo en el contacto con el otro, mediante la metáfora de las letras y las palabras, este fragmento presenta también la escritura (el hecho de pegar una letra con otra para formar palabras) como una escapatoria del yo. Escribir, como lo hace el personaje, un cuento inspirado por un sueño místico tiene también la peculiaridad de presentar otra faceta del yo, la del subconsciente. Sea en la escritura de un cuento inspirado por un sueño místico o en la conversión religiosa al sufismo, el personaje narrador busca aquí aparentemente trascenderse a sí mismo, superar los límites de la singularidad del yo.

En el tercer y último relato de El Gran Vidrio, el narrador -que en buena parte del capítulo se convierte en narradora- cambia de identidad y de rostro a su antojo y según las circunstancias, en una auténtica afirmación de la consabida fórmula rimbaldiana: "Yo es otro". Uno de sus semblantes es el de una niña de cuarenta y seis años cuya familia vive constantemente bajo la amenaza de ser expulsada de su casa, amenaza que se cumple en forma repetida. En varias 
ocasiones, y por iniciativa de su padre, la niña entabla un baile desenfrenado, disfrazándose cuidadosamente para la ocasión, con el fin de enternecer a los propietarios y así retrasar la expulsión: "Recuerdo que al arrendador solían sentarlo en uno de los cojines principales, furioso, y yo comenzaba a mover mi cuerpo haciéndome pasar por una verdadera marioneta" (126). Si el disfraz en sí implica la adopción de una identidad ajena y el rechazo de la propia, disfrazarse de marioneta es aún más significativo, pues representa una alienación particular: el cambio de identidad por la de un títere sin voluntad propia ni autonomía, que necesita la intervención ajena para animarse (en todos los sentidos de la palabra, incluyendo el más etimológico²). Finalmente, cuando se da la orden de desalojo la niña agrega: "Yo entretanto debía desenredar las cuerdas que me habían convertido en marioneta por unas horas, sin saber dónde refugiarme" (127). Ya sean o no voluntarias, ineludibles, temidas o impuestas, estas metamorfosis entran en la construcción y en la evolución de la identidad del yo: modifican su percepción de sí mismo o, al contrario, su percepción de sí mismo genera una metamorfosis, como es el caso de la conversión religiosa o de los cambios radicales de identidad del narrador-narradora.

Por otra parte, si bien el sacrificio de la castración tiene que ver con una mutilación identitaria de la víctima, los investigadores del llamado caso de los Hombres Castrados en La muerte me da tienden a explicar las motivaciones del asesino por un "deseo de alteridad" (243). Dicha explicación ahonda en la posibilidad de que efectivamente la castración sea un intento del asesino de conectarse con el

\footnotetext{
${ }^{2}$ El latín establecía una división fundamental y primordial entre los sustantivos: animado e inanimado, es decir, literalmente, lo que está dotado de un alma y lo que no. El simple hecho de decir yo nos plantea en aquella primera categoría, dentro de la cual existen muchas otras categorías (hombre-animal, masculino-femenino, etc.), muchas alteridades, pero esta primera división representa de alguna manera la alteridad absoluta, la que prima sobre todas las demás. Disfrazarse de marioneta, y por tanto pasar a la categoría de lo inanimado, es decir al mundo de los objetos, representa pues una alienación extrema.
} 
otro, expulsándolo "fuera de sî", como lo sugiere la lectura, a la luz de la teoría de Bataille, del mensaje de la Viajera del Vaso Vacío citado supra. El sexo, así como los ojos, fungen como puerta de entrada al otro, que permite no solamente "saber qué pasa allá adentro" (145), sino también adentrarse en el otro, ser parte de él y hacerlo parte de uno, asimilarlo hasta no poder distinguir el yo del otro, al hombre de la mujer, como lo expresa Cristina: "Iba a sonreír. Iba a convertirme yo misma en una Amante de Sonrisa Iluminada cuando no vi su pene que, perdido dentro de mi sexo, continuaba provocando placer (...) $\mathrm{Su}$ pene en esos momentos era mío. Entonces sonreí hermafroditamente" (59). De la confusión física que nace de la abolición de las fronteras entre el yo y el otro, surge esta tentación de la conversión en el otro, que se entiende finalmente como una tentativa de absorción del otro, una fusión del yo con el otro. En este caso el acto sexual le procura a la protagonista un sentimiento de completitud; pero en el caso de El-Hombre-Que-Era-Él-A-Veces, el mismo deseo sexual de alteridad tiene otro origen:

Colocó un billete bajo el zapato de plataforma y, ya de pie, arrojó su mano hacia el interior del cuerpo femenino. La tibieza. La humedad. Lo que había imaginado. Deseó estar más adentro. Deseó entrar completamente. Suplantarla. Ser la mano que se protege del frío bajo la tela del guante. Ser ella. Ocluirla. Ser el cuerpo secreto de la mujer. Ver por sus ojos. Sentir lo que ella estaba sintiendo. Abierta. Habitada. (264)

Aquí el deseo de alteridad revela una necesidad de huir de sí mismo, de convertirse en otro para dejar de ser yo, una voluntad de diluirse en el otro para eludirse a sí mismo. Se puede establecer un paralelismo entre este deseo de alteridad provocado en estas líneas por el erotismo carnal, y la dinámica de la lectura, en la cual el lector también "[desea] estar más adentro" y busca perderse en la alteridad, quizás como se busca una escapatoria, una breve alternativa a uno mismo... Barthes escribe en 1973:

[...] le plaisir du strip-tease corporel ou du suspense narratif. Dans l'un et l'autre cas, pas de déchirure, pas de bords: un 
dévoilement progressif : toute l'excitation se réfugie dans l'espoir de voir le sexe (rêve de collégien) ou de connaître la fin de l'histoire (satisfaction romanesque). $(18)^{3}$

Comparar el erotismo con la literatura o el placer sexual con el placer textual no es nada inédito; sin embargo, nos interesa subrayar brevemente lo que puede representar desde la perspectiva de la dialéctica yo-otro: en uno y otro caso, la excitación referida por el filósofo nace de un movimiento hacia el otro, hacia lo desconocido, fuera de sí.

\section{El desdoblamiento: alter ego o alternativa a sí mismo}

La importancia de la metamorfosis en estas dos novelas culmina con el motivo del desdoblamiento, que surge de modo recurrente aunque no sistemático, pues sus manifestaciones son múltiples. En la novela de Cristina Rivera Garza, tanto Valerio como la Detective conversan con un ser imaginario y diminuto, simulacro de interlocutor que les confiere a sus monólogos unos atisbos dialógicos. Esta creación mental fantasiosa le sirve de soporte y de vector a la introspección de ambos personajes. Se presenta a veces como un reflejo de los sentimientos o deseos de los protagonistas, como un apoyo comprensivo; en otras ocasiones, es un juez tanto más crítico que, siendo una proyección del yo, un auténtico álter ego, conoce sus secretos más recónditos. Alternativamente nombrada La Mujer Increíblemente Pequeña, La Dama Pequeñísima y Grildrig ${ }^{4}$, esta figura tiene una función múltiple y una interesante simbología.

\footnotetext{
${ }^{3}$ [...] el placer del strip-tease corporal o del suspenso narrativo. En uno y otro caso no hay desgarradura, no hay bordes, sino un desvelamiento progresivo: toda la excitación se refugia en la esperanza de ver el sexo (sueño del colegial) o de conocer el fin de la historia (satisfacción novelesca) (El placer del texto 19-20).

${ }^{4}$ Nombre que le asignaron a Gulliver al inicio de su estancia en Brobdingnag, el país de los gigantes, en el que él era, por contraste, infinitamente pequeño.
} 
En el marco de un estudio sobre la importancia de la alteridad en la construcción del yo y la introspección, se puede mencionar que reactiva la figura del amigo imaginario de la infancia, aquel interlocutor y cómplice ideal con el que sueñan los niños y que les permite establecer una relación dialógica satisfactoria y cómoda, en la que controlan los dos polos del intercambio. Si bien no es suficiente para el desarrollo del individuo, que necesita enfrentarse con una verdadera alteridad, ese ser imaginario puede permanecer inmaterial o encarnarse en un peluche o en cualquier objeto que adquiera una fuerte carga sentimental. Representa un compromiso, una etapa intermediaria entre el yo y la alteridad. Es una forma de alteridad propia: le permite al niño reproducir una situación dialógica sin salir fuera de sí. La reactivación de esta figura en la novela provoca la aparición de un "monodiálogo" o de un diálogo íntimo. A la vez que significa la emergencia dentro de la esfera del yo de un representante de la alteridad propia, de un alter ego, dicho diálogo íntimo permite paradójicamente consolidar la dinámica autárquica del proceso introspectivo del personaje. Este sustituto de alteridad permite y legitima la ausencia del otro.

Por otra parte, sus dimensiones minúsculas no son únicamente anecdóticas. Sería asimismo poco afortunado pensar que sólo simbolizan la incomprensión crónica de un individuo en un mundo "ancho y ajeno". El motivo de la miniatura, genéricamente hablando, tiene como correlativo el de la dicotomía microcosmos-macrocosmos, explica Bachelard, quien lamenta: "Le psychologue -et a fortiori le philosophe- donne peu d'attention aux jeux de miniatures qui interviennent souvent dans les contes de fées" (La poetique de l'espace 140). ${ }^{5}$ La concentración de los valores en la miniatura la convierte en una réplica sintética, la quintaesencia del modelo de tamaño original, y la pérdida de las dimensiones permite además mayor libertad de

5 “"El psicólogo -y a fortiori el filósofo- presta poca atención a los juegos de las miniaturas que intervienen con frecuencia en los cuentos de hadas" (La poética del espacio 136). 
imaginación. Al alejarse de lo real, condensa los aspectos más importantes, en detrimento de su proporción o importancia original. En el caso de la novela de Rivera Garza, este rasgo ahonda en la soledad y la dinámica introspectiva del personaje.

En varias ocasiones, Grildrig pide un bosque y lo justifica por su necesidad de descansar (Rivera 267). Casualmente, Bachelard explica que el bosque siempre ha sido asimilado a la inmensidad, a la profundidad, y por ende a un lugar de senderos múltiples en el que es fácil extraviarse. Si el bosque se entiende claramente como la antítesis de la gran ciudad, con su ajetreo y sus atrocidades, por lo que representa el lugar idóneo para un descanso físico y espiritual, tiene también connotaciones psicológicas, tal como lo pretenden los franceses Marcault y Brosse en 1939, citados por Bachelard: "La forêt surtout, avec le mystère de son espace indéfiniment prolongé audelà du voile de ses troncs et de ses feuilles, espace voilé pour les yeux, mais transparent à l'action, est un véritable transcendant psychologique" (Bachelard 170) ["El bosque sobre todo, con el misterio de su espacio indefinidamente prolongado más allá del velo de sus troncos y de sus hojas, espacio velado para los ojos, pero transparente a la visión, es un verdadero trascendente psicológico" (Bachelard 165)].

A su vez, Bachelard explica: "Il n'est pas besoin d'être longtemps dans les bois pour connaitre l'impression toujours un peu anxieuse qu'on 's'enfonce' dans un monde sans limite. Bientôt, si l'on ne sait où l'on va, on ne sait plus où l'on est" (170) ["No hace falta pasar mucho tiempo en el bosque para experimentar la impresión, siempre un poco angustiada de que 'nos hundimos' en un mundo sin límite. Pronto, si no se sabe a dónde se va, no se sabe tampoco dónde se está" (165)]. El bosque no sólo representa un remanso de tranquilidad, sino también el espacio por antonomasia y quizás la metáfora de la indagación psicológica de los protagonistas que sondean sus adentros, su propia profundidad, y se sumen, con angustia, en un entramado de deseos, miedos y sentimientos complejos y a veces oscuros. Todos estos aspectos, algunos más evidentes que otros, contribuyen a hacer de esta figura diminuta, misteriosa y fantástica un vector privile- 
giado de la introspección que tanto Valerio como La Detective emprenden naturalmente a la par que investigan el caso criminal.

En otras ocasiones, brota otra figura -fugaz- de doble del personaje: "Me lo pregunté en silencio y en voz alta. Me lo pregunté a mí misma y a la ventana en que, distorsionado, mi reflejo me lo preguntaba a su vez. Se lo pregunté al paisaje confundiendo a los álamos de la tarde con altos olmos europeos" (Rivera 74). Este reflejo mimético de Cristina resume perfectamente la razón de ser de estos dobles imaginarios: en su dinámica introspectiva, los protagonistas de $L a$ muerte me da se enfrentan con la incomprensión de buena parte de su entorno y sobre todo con su propia soledad existencial, misma que genera el "deseo de alteridad" de todos y cada uno, ya fueran asesinos, escritores, detectives o víctimas, quienes cuando fueron asesinadas salían "en busca de algo [...] Algo distinto" (113). Los dobles imaginarios de los protagonistas, efímeros o dotados de un espesor narrativo, tienen vocación de sustituir la alteridad ausente o de crear la ilusión de una alteridad satisfactoria, que corresponda exactamente con las expectativas del yo, capaz de una comprensión y empatía total.

Otras creaciones fantasiosas son las múltiples identidades ostentadas en los distintos mensajes escritos por la Viajera del Vaso Vacío, quien asume el papel del asesino y cuya identidad nunca se descubre. Utiliza alternativamente los nombres de Joachima Abramövic, Gina Pane y Lynn Hershman, que tienen en común sus consonancias extranjeras -símbolo por antonomasia del otro-, y el designar a tres artistas femeninas que se conocen por sus performances extremas sobre el cuerpo mutilado. Esta adopción sucesiva de varias identidades, especialmente tratándose de identidades ajenas reales, revela que el proceso de construcción de la identidad propia radica aquí esencialmente en la imaginación, la invención, y el "deseo de alteridad". El caso de Joachima Abramövic es aún más representativo de este fenómeno, porque la narradora sólo adopta el apellido de la artista Marina Abramövic, inventándole un nuevo nombre. Se trata, en cierto modo, no solamente de una identidad ajena, sino también de una identidad alterada, alter-ada, que llega así a los extremos de la alteridad. 
El otro, lo ajeno, se convierte entonces en componente de la construcción o de la invención de sí. Pone asimismo de relieve las carencias intrínsecas de un yo que es incapaz de definirse sin recurrir a un modelo, sin inspirarse en el otro. Más que un puro elemento de comparación que le permite afirmar por contraste su diferencia, su carácter único, el otro se convierte aquí en la materia prima de ese yo inestable e inseguro que confiesa: "Me llamo Joachima Abramövic. Y no sé, en realidad, quién soy" (79). Su inestabilidad y quizás su inconformidad con las identidades que adopta se traducen en las personas verbales que emplea: utiliza alternativamente la primera, segunda y tercera persona del singular a medida que se apropia o se desprende de cada uno de los tres nombres:

Lynn lleva un sombrero de fieltro. Lynn lleva un saco de lana, dos botones de nácar en la cintura entallada. Lynn lleva guantes de cachemira blanca. Lynn camina lentamente, contoneándose. (...)

Me llamaba Lynn Hershman, Pero todo muere, Cristina, ¿te acuerdas? Todo cansa.

Ay, Lynn, cómo te amé. $(89,90)$

Finalmente, concluye entre burlona y decepcionada por el fracaso de su búsqueda identitaria: "Mi nombre es Lynn. Lynn Hershman. Y mi nombre, como te lo imaginas, como lo sabes, como en tu propio caso, mi nombre no soy yo" (92). Puede uno preguntarse entonces si todo no habrá sido más que un juego de disfraces, la búsqueda de diversión de un personaje profundamente aburrido de sí y del mundo. Ello no iría sin recordar la novela de Jean Giono Un rey sin diversión (1946), que concluye con la cita de Pascal: "un rey sin diversión es un hombre lleno de miserias" (137, la traducción es mía), y en la que el protagonista mata sólo porque la sangre roja representa una alternativa a la nieve blanca que lo cubre todo y lo aburre tremendamente.

Este aspecto lúdicamente esquizofrénico del cambio sistemático de identidad es muy notable en la obra de Mario Bellatin, cuyo subtítulo "Tres autobiografías", firmadas por un solo autor, sugiere la 
presencia de varios avatares o dobles del narrador. Los narradores de los tres capítulos son muy distintos unos de otros, pero acaban por fundirse y confundirse en la figura de un narrador proteiforme y mutante. Es así como el narrador o narradora del último relato asume varias identidades y admite cierta tendencia a la afabulación: "Creo que soy algo mentirosa" (135), y afirma poco después: "Una de las características principales de mi personalidad es mentir todo el tiempo" (146). Acumula los desmentidos y las reafirmaciones de lo que había desmentido líneas antes y se presenta a veces bajo el aspecto de un "joven de lentes cuadrados" (154), a veces como una niña de cuarenta y seis años e incluso bajo los rasgos del propio escritor Mario Bellatin, hasta que estas identidades incompatibles se mezclan con las figuras anteriores, es decir el niño de la piel brillante y el escritor convertido al islam sufí. Se establece entonces un auténtico juego de sillas musicales entre las diferentes identidades, que se excluyen entre sí pero conviven dentro de un yo único. Por eso parece curiosamente eufemística la declaración: "en realidad no soy más que una grácil marioneta popular. Hay como dos personas en mí” (154). En El Gran $V i d r i o$ el yo cambia de semblante y se convierte en un territorio movedizo constituido por la combinación inestable de muchas identidades, ajenas unas a otras, suma de alteridades propias que se rozan y se enfrentan en el placer de la invención continua y frenética de sí.

Los ejemplos de metamorfosis o de disfraz mediante la ficción novelesca o la ficcionalización del yo narrador, así como la creación mental de un doble-espejo (sustituto de alteridad) o de un dobleavatar ( yo alternativo), ponen de realce la importancia de la imaginación en el proceso de construcción de la identidad del yo, especialmente para suplir la alteridad ausente o insuficiente, o para eludir los límites de un yo singular.

\section{Conclusión}

La alteridad se convierte en estas dos novelas en un componente ineludible y polifacético del proceso de introspección y de construcción del yo narrador. Las figuras del otro adoptan distintas formas y 
tienen distintas funciones o efectos. Está en primera instancia el otro inalcanzable, ese otro que por su ausencia o indiferencia no permite la construcción del yo por el diálogo. Lejos de acabar con el yo, este otro ausente lo obliga, para salvarse, a desplegar un sinfín de recursos para sustituir la alteridad faltante y compensar esta carencia. Así, unos personajes se refugian en el monólogo interior, en el sueño y la invención de sí mismo. Otros crean mentalmente un alter ego que le brinda una dimensión dialógica a su dinámica introspectiva y se convierte por ello en un vector de autoexploración. Finalmente, es difícil distinguir al yo auténtico de un yo inventado o soñado, producto del subconsciente, del delirio o de la ficción; estos alter ego pueden ser incluso tan o más auténticos y sinceros que el yo que los alberga y los fantasea. El otro, real o imaginario, además de representar un elemento de comparación contrastiva con el yo, se convierte en numerosas ocasiones en una alternativa a sí mismo, en una vía de escape para soñarse otro, realizarse otro en el sueño o la ficción.

Estas alteraciones de la identidad propia conducen a esbozar un yo mutante, que afecta la credibilidad de la instancia narradora y la estabilidad de la focalización narrativa. Pasando por el prisma de esas subjetividades alteradas -alienadas-, la narración se convierte en estas dos novelas en un rompecabezas, y el personaje narrador en un jardín de senderos que se bifurcan y proliferan. El texto y el individuo padecen los mismos síntomas: el individuo se concibe como un texto en proceso de escritura, del que se pueden borrar, corregir, modificar, agregar o quitar datos, con la libertad vertiginosa que proporciona una página en blanco. La noción de identidad se desprende entonces de toda determinación o limitación para abarcar, en el reino de la ficción, el infinito campo de los posibles. La identidad personal, como la obra, rechaza todo intento de cierre o conclusión, permanece abierta, en proceso inacabado de realización. El texto, por su parte, se contagia del libre albedrío que caracteriza tradicionalmente a los individuos, particularmente al sujeto moderno, y escapa de este modo de las normas narrativas consabidas y del canon para bifurcar a su vez y proliferar laberínticamente al ritmo de las mutaciones discursivas e identitarias. Al texto le da por mentir y desmentir a su antojo, juguetón y bromista, mientras que el individuo se 
escribe, revelando su esencia de fantasía textual de papel y tinta. La alteridad intrínseca del yo o fantaseada por él tiene su correlación en la alteración genérica y discursiva del texto: al fin y al cabo, ambos resultan ser criaturas híbridas.

A la par que el texto se apodera de obras ajenas, las reescribe, se "intertextualiza", el individuo roba identidades ajenas, las hace suyas, las mezcla, las reactualiza y se empapa de ellas en un proceso de mutuo contagio. Tanto a nivel textual como de los personajes, resulta una identidad hecha pedazos, o mejor dicho hecha de pedazos, apenas coherente y sobre todo múltiple, que desborda las fronteras individuales de la obra o del yo. Es una identidad compuesta de una colección de identidades distintas, a la manera de un caleidoscopio; asimismo, el relato retoma una serie de textos ajenos, de la cultura colectiva, reutilizados hasta el cansancio. Textos e identidades cambian así de cuerpo y dueño, cuales unos cangrejos ermitaños. A la vez que el texto es genérica y discursivamente movedizo y que va cambiando de aspecto, la identidad camaleonea a su antojo, brincando de un semblante y nombre a otro, inestable, deforme, monstruosa.

Estas duplicaciones y mutaciones identitarias, esta alienación de lo propio y otras variaciones sobre el tema del "yo es otro", se convierten en unas de las múltiples manifestaciones de la subversión de las formas canónicas de la escritura narrativa y, especialmente, de las escrituras del yo. La regla de la unidad de tiempo, lugar y acción, típica del teatro clásico y defendida entre otros por Boileau en su Arte poética (1674), estuvo en debate durante dos siglos y su abandono progresivo constituyó una transgresión y una considerable evolución del género dramático. Estas novelas de Cristina Rivera Garza y Mario Bellatin plantean hoy la obsolescencia de la unicidad de la identidad individual, llevando al extremo la desconfianza de muchos críticos y autores desde inicios del siglo XX sobre la pretensión decimonónica de la autobiografía de postular un yo único y coherente a pesar del paso del tiempo. 


\section{Bibliografía}

Bellatin, Mario. El Gran Vidrio. Barcelona: Anagrama, 2007.

Rivera Garza, Cristina. La muerte me da. México: Colección Andanzas, Tusquets Editores, 2007.

Bachelard, Gaston. La poética del espacio. Tr. Ernestina de Champourcin.

Buenos Aires: FCE, 2000.

. La poétique de l'espace (1957). Paris: PUF, 2009.

Bajtín, Mijaíl M. Yo también soy (Fragmentos sobre el otro). Tr. Tatiana

Bubnova. México: Taurus, 2000.

Barthes, Roland. Le plaisir du texte. Paris: Éditions du Seuil, 1973.

. El placer del texto. Tr. Nicolás Rosa. México: Siglo Veintiuno Editores, 1993.

Bataille, Georges. La mutilation sacrificielle et l'oreille coupée de Vincent Van Gogh. Paris: Allia, 2006.

Deleuze, Gilles y Félix Guattari. Kafka. Por una literatura menor. Tr. Jorge Aguilar Mora. México: Era, 1978.

Giono, Jean. Un roi sans divertissement. Paris: Gallimard, 1972.

Pascal, Blaise. Pensamientos. Madrid: Cátedra, 1998.

Rimbaud, Arthur. Lettres “du Voyant” à Georges Izambard et à Paul Demeny. 13, 15 de mayo de 1871. 